\title{
Uma exposição sobre a física dos esportes pelo olhar de adolescentes: um estudo de caso no Museu Ciência e Vida
}

\author{
Jessica Norberto Rocha ${ }^{1}$ \\ Fundação Centro de Ciências e Educação Superior a Distância \\ do Estado do Rio de Janeiro \\ Eliza Cabral ${ }^{1}$ \\ Bolsista TCT da FAPERJ \\ Instituto Nacional de Comunicação Pública da Ciência e Tecnologia \\ Luisa Massarani ${ }^{1}$ \\ Fundação Oswaldo Cruz \\ Priscila Coelho ${ }^{1}$ \\ Mestranda em Divulgação Científica \\ Fundação Oswaldo Cruz \\ Mônica Dahmouche ${ }^{1}$ \\ Fundação Centro de Ciências e Educação Superior a Distância \\ do Estado do Rio de Janeiro \\ Rio de Janeiro - RJ
}

\section{Resumo}

Analisamos a experiência de cinco grupos de adolescentes em uma exposição sobre a física dos esportes, visando compreender como eles interagem com os mediadores, a exposição e entre si, bem como o conteúdo de suas conversas. A visitação foi gravada com uma câmera subjetiva e analisada a partir de um protocolo de pesquisa. Na análise, observamos que a interação dos visitantes com os mediadores prevaleceu à interação dos visitantes entre si, especialmente, nas conversas voltadas para a temática científica, associações com experiências anteriores e conversas sobre o desenho e uso dos objetos expositivos. $O$ estudo sinaliza que a exposição conseguiu mobilizar os adolescentes em torno de temas de ciência e a escolha do tema

\footnotetext{
${ }^{+}$An exhibition about the physics in sports through the eyes of adolescents: a case study at Museu Ciência e Vida

* Recebido: março de 2020. Aceito: junho de 2020.

${ }^{1}$ E-mails: jessicanorberto@yahoo.com.br; elizacunhacabral@gmail.com; luisa.massarani7@gmail.com; priscilarabit@yahoo.com.br; monicacecierj@gmail.com
} 
"esportes" parece ter ajudado nesse sentido. A pesquisa fornece subsídios para reflexão a respeito dos modos de mediar exposições de ciências e desafios a serem explorados em estudos futuros e em práticas de formação de mediadores. Esperamos que este estudo seja um passo importante para o fomento à cultura dos adolescentes de frequentar espaços científico-culturais, uma vez que busca compreender interesses, conversas, modos de interagir.

Palavras-chave: Adolescentes; Museus de Ciências; Física; Esportes.

\begin{abstract}
We analyze the experience of five groups of teenagers in the exhibition about the physics of sports, aiming to understand how they interact with the explainers, the exhibition and with each other, as well as the content of their conversations during the visit. The groups' routes were recorded with a subjective camera and analyzed using a research protocol. In the analysis, we observed that the interaction of visitors with the explainers prevailed over the interaction of visitors with each other, especially in conversations focused on scientific issues, associations with previous experiences and conversations about the design and use of exhibition objects. The studies indicate that the exhibition managed to engage teenagers around scientific issues and the choice of the theme "sports" seems to have helped in this regard. The study provides subsidies for reflection on the ways of mediating science exhibitions and challenges to be explored in future studies and in training for explainers. We expect this study to be an important step in fostering the culture of adolescents in attending scientific-cultural spaces, since it seeks to understand interests, conversations, ways of interacting.
\end{abstract}

Keywords: Teenagers; Science Museums; Physics; Sports.

\title{
I. Introdução
}

Os esportes estão presentes na vida de brasileiros e brasileiras, em uma partida de futebol na praça, na caminhada diária, na pedalada do final de semana e/ou na atividade física realizada na escola. Os meios de comunicação de massa, uma das fontes de informações científicas mais importantes dos cidadãos (CGEE, 2019), sistematicamente veiculam informações sobre esportes. Na TV, por exemplo - presente em 97,2\% dos lares brasileiros, segundo o Instituto Brasileiro de Geografia e Estatística - há uma grande quantidade de 
canais que transmitem competições esportivas de todas as modalidades, além de especialistas que fazem comentários sobre os resultados dos jogos e dos atletas (CGEE, 2019).

A tecnologia vem sendo amplamente usada nos esportes, um exemplo, é o desenvolvimento de novos tecidos que contribuam para a performance dos atletas. Entretanto, o uso mais efetivo de fato, é o monitoramento dos atletas, já é possível medir a força do saque, do chute, o impacto das bolas, as trajetórias dos arremessos, profundidade dos mergulhos, dentre outros. Esses dados que constituem uma avaliação do atleta, contribuem para o acompanhamento de sua performance e melhoria de seu desempenho. No entanto, pouco se fala sobre os conceitos físicos que envolvem o universo esportivo (SANTIAGO et al., 2009). O que poucos sabem é que esse acompanhamento só é possível porque conhecemos as leis da Física que regem o movimento dos atletas: velocidade, força, atrito, inércia são fatores que influenciam diretamente nas práticas esportivas.

Os esportes estão, também, entre os temas de maior interesse entre os jovens brasileiros: $62 \%$ dos entrevistados em estudo realizado pelo Instituto Nacional de Comunicação Pública da Ciência e Tecnologia responderam ter interesse por essa área [MASSARANI et al., 2019]. Esse estudo foi realizado com 2.206 jovens com idades entre 15 e 24 anos residentes de todas as regiões do Brasil, utilizando como metodologia de survey, com as entrevistas realizadas por uma equipe treinada no início do ano de 2019. O mesmo estudo mostra que $67 \%$ dos entrevistados também expressam interesse em temas de ciência.

Nesse contexto, pesquisadores, professores e divulgadores da ciência vêem nos esportes uma boa oportunidade para engajar jovens em temáticas científicas e, por isso, os têm associado a iniciativas de ensino formal e não formal na área de física (ver BASTOS; MATTOS, 2009; MICHA; FERREIRA, 2013; VOURLIAS; SEREGLOU, 2016; DUARTE; OKUNO, 2012; ALMEIDA; SILVA, 2015). Duarte e Okuno (2012), por exemplo, utilizam o futebol para explicar conceitos da mecânica. Segundo eles, futebol e física são inseparáveis e:

Entender a Física do futebol provavelmente não vai fazer ninguém jogar melhor, mas com certeza vai ajudar a compreender um pouco mais esse jogo fascinante. E para quem quer compreender as leis do movimento, estudar a Física do futebol é a maneira mais descontraída de fazê-lo (DUARTE; OKUNO, 2012, p. 7).

Utilizando também o futebol como tema, Santiago, Martins e Neto (2010) desenvolveram uma metodologia para dar suporte a um professor de pré-vestibular comunitário no ensino de física. Os autores utilizaram recortes de vídeos de partidas de futebol para contextualizar conceitos da mecânica newtoniana, vistos anteriormente de forma teórica pelos alunos. Para os autores, "é desejável que o ensino de Física seja voltado para a compreensão da vida e para a resolução de problemas do dia a dia, que seja trabalhada a partir do cotidiano vivencial dos estudantes" (SANTIAGO; MARTINS; NETO, 2010, p. 9).

Em seu estudo, Vourlias e Seroglou (2016) investigaram como a física e os esportes podem ser trabalhados de forma conjunta no ensino para estimular o interesse dos estudantes e promover a aprendizagem fora da sala de aula. Para isso, os autores fizeram atividades em 
que os alunos realizavam movimentos feitos por atletas de diferentes esportes, como corridas, saltos e chutes a gol. Durante a execução dessas atividades, os alunos eram monitorados por alguns aparelhos eletrônicos para mensurar suas performances. Depois analisaram os resultados relacionando-os com os conceitos físicos envolvidos nas atividades. Os autores concluíram que o método utilizado para o ensino desses conceitos nesse estudo foi apreciado pelos alunos, aumentando sua participação e seu interesse pelo tema. Além disso, segundo os autores, o curso encorajou os estudantes a perceberem que podem usar a ciência para explicar os esportes que eles gostam.

Na mesma linha, Sojourner, Burgasser e Weise (2018) desenvolveram um plano de aula em que os alunos trabalharam conceitos de física realizando movimentos de ginástica. Após a execução das atividades, os estudantes foram questionados sobre suas performances e sobre os conceitos físicos nelas envolvidos, como energia e posição de seus corpos, e como essas questões influenciaram na execução de seus movimentos. Segundo os autores, os adolescentes demonstraram mais interesse em ginástica do que na física antes da realização das atividades. Porém, o interesse por física aumentou bastante e ultrapassou o da ginástica após a aula.

Os dois estudos citados anteriormente retratam o teste de teorias baseadas nas leis da física que regem os movimentos, como uma aula experimental, permitindo que os alunos verifiquem a validade das equações que regem os movimentos dos corpos sob ação da gravidade, além de conhecerem os conceitos de erros inerentes às medidas, o que não é discutido quando a abordagem é apenas teórica. Os conceitos de física são tratados na maioria das escolas apenas sob a ótica da teoria mantendo os estudantes pouco habituados aos experimentos o que pode levar à frágil apropriação dos conceitos.

Iniciativas que abrangem situações do cotidiano tendem a beneficiar o aprendizado de novos conceitos na medida em que se relacionam com o contexto vivido pelos estudantes. Muitas abordagens de ensino-aprendizagem têm aparecido neste sentido evidenciando que a interdisciplinaridade e a experimentação podem ampliar consideravelmente o interesse e o aprendizado dos alunos pelos conceitos de física (BASTOS; MATTOS, 2009). No que diz respeito aos museus, apesar de ciência e esporte ser um tema que tem sido, em alguma medida, abordado na América Latina em exposições nos últimos anos ${ }^{2}$ - especialmente por conta da Copa do Mundo de Futebol Masculino e dos eventos Olímpicos que aconteceram no Brasil, respectivamente em 2014 e em 2016 - ainda há poucos estudos publicados.

No Brasil, Almeida e Silva (2015) discutiram experimentos desenvolvidos e apresentados na oficina "aerodinâmica de bolas" parte da exposição "Ciência do Esporte", realizada no centro de ciências Espaço Ciência Viva da cidade do Rio de Janeiro no ano da Copa do Mundo. Nessa oficina era mostrado como as leis da física agiam sobre bolas de diferentes formatos, prever possíveis resultados, realizar experiências, além de discutir e

\footnotetext{
${ }^{2}$ A partir de algumas visitas técnicas em 2018, observamos que também há exposições sobre ciência e esportes em museus colombianos, como o Parque Explora (Medellín) e o Maloka (Bogotá).
} 
buscar significados científicos. Segundo Almeida e Silva $(2018$, p.5) “(...) atividades desta natureza deveriam ser valorizadas e disseminadas, particularmente considerando que centros de ciência contribuem para a melhoria da educação de um cidadão."

Diante desse contexto e grande potencial de engajamento de adolescentes na temática ciência e esportes, neste artigo, analisamos a experiência vivida por cinco grupos de adolescentes na exposição "Movimente-se! A física dos esportes" que relaciona as Leis de Newton com os esportes, visando compreender como eles interagem com os mediadores, a exposição e entre si, bem como o conteúdo de suas conversas durante a visita.

A exposição foi organizada por uma equipe multidisciplinar - físicas, divulgadores da ciência e museóloga - do Museu Ciência e Vida (MCV) da Fundação Centro de Ciências e Educação Superior à Distância do Estado do Rio de Janeiro (Fundação Cecierj), localizado no município de Duque de Caxias, no Rio de Janeiro. O contexto em que esse museu está localizado é bastante particular porque ele é localizado na Baixada Fluminense, região de pouca oferta de museus e centros de ciência. De acordo com o Guia de Centros e Museus de Ciência do Brasil (ALMEIDA et al., 2015) há cerca de 50 espaços científicos culturais no Rio de Janeiro, sendo apenas dois na Baixada Fluminense. Essa pouca oferta de instituições museais reflete nos hábitos culturais da população. Em pesquisa realizada em 2014 com 340 pessoas da cidade com mais de 12 anos (perfil da amostra que seguiu dados do Censo do IBGE) (LEIVA, 2014), visitar museus não foi uma opção mencionada pelos participantes quando se perguntou o que a pessoa mais gostava de fazer no tempo livre, $29 \%$ declarou nunca ter visitado um museu e apenas $18 \%$ declarou ter visitado alguma instituição museal no ano anterior à pesquisa.

\section{Metodologia}

Esse estudo se insere no escopo do Instituto Nacional de Comunicação Pública da Ciência e Tecnologia, com apoio do CNPq e da Faperj, e Musa Iberoamericana: Red de Museos y Centros de Ciencia, com apoio do Cyted. Essa pesquisa sobre o "Olhar do visitante" tem sido desenvolvida em diversos museus da região da Iberoamérica e tem como objetivo desenvolver estratégias e ferramentas para compreender a experiência museal do ponto de vista dos visitantes, em particular adolescentes em grupos de amigos, fora do contexto de visita escolar (MASSARANI et al., 2019a, 2019b, 2019c, 2019d).

\section{Universo de estudo}

A exposição "Movimente-se! A física dos esportes" possui 700 metros quadrados, é dividida em dois espaços. No primeiro espaço, o "Estádio do Conhecimento", há painéis expositivos que explicam as Leis de Newton, relacionando-as com esportes olímpicos e paraolímpicos e um módulo interativo de realidade virtual envolvendo bolas e a marca do museu. Também são expostos uniformes de alguns esportes autografados por atletas, além de 
uma mesa de pebolim. No segundo espaço, a "Arena Olímpica”, há painéis que falam sobre alguns esportes olímpicos que são simulados em atividades interativas como: uma pista de corrida reproduzindo o atletismo; uma cadeira giratória e uma trave replicando a ginástica olímpica; um jogo de videogame simulando a natação; uma pequena quadra com um gol e bolas com sinos para praticar o futebol de cinco; mesas com jogos de botões e uma pequena quadra de vôlei imitando o vôlei sentado. Além desses espaços, há uma sala, parecida com um pequeno cinema, na qual é reproduzida uma reportagem sobre o uso da ciência e tecnologia no desenvolvimento dos atletas. A exposição é parcialmente acessível, por meio de módulos interativos, tais como o chute a gol com a bola de guizo acessível a cegos e tablets com explicações em língua de sinais e audioguias.

Do ponto de vista de concepção e design, a exposição se insere na concepção de interatividade física, caracterizada pela manipulação de módulos expositivos Wagensberg (2000), como é o caso das atividades em que os visitantes podem simular a prática de alguns esportes olímpicos e paraolímpicos (Arena Olímpica). Possui também um espaço em que ocorrem interações do tipo contemplativo (ROCHA, 2018), com painéis, fotos e objetos que estimulam a leitura e a contemplação (Estádio do Conhecimento).

\section{III.1 Sujeitos da pesquisa e coleta de dados}

Neste estudo, para selecionar os sujeitos de pesquisa utilizamos uma amostra não probabilística que usa cadeias de referência chamada "amostragem por bola de neve" (do inglês snowball sampling), muito usada em pesquisa social de caráter qualitativo e útil quando a pesquisa envolve questões pessoais dos participantes da pesquisa (BERNARD, 2005; BIERNARCKI; WALDORF, 1981).

Assim, foram convidados cinco grupos compostos por duas meninas e dois meninos, de 14 a 17 anos, totalizando 20 adolescentes, para participar da pesquisa que ocorreu durante a visitação à exposição do MCV. Desses, quatro adolescentes tinham 14 anos, dez 15, três 16 e três 17 anos. Como podemos observar na Tabela 1, um adolescente estava no quinto ano do Ensino Fundamental, um no sexto ano, dez no nono ano do Ensino Fundamental, quatro no primeiro ano do Ensino Médio e quatro no terceiro ano do Ensino Médio. Todos os participantes eram de escolas públicas, da rede municipal e estadual, e residiam em Duque de Caxias, Belford Roxo e São João de Meriti, cidades da região metropolitana do Rio de Janeiro, Baixada Fluminense.

Em cada grupo, um adolescente foi convidado a colocar uma câmera do tipo GoPro na cabeça a fim de registrar a experiência museal. Esse método de coleta de dados é caracterizado como "câmera subjetiva", pois que permite captar a imagens e sons a partir do ponto de vista do sujeito e vem sendo utilizado em diversos estudos na área de ciências sociais (LAHLOU, 2011; GLĂVEANU; LAHLOU, 2012; SPINNEY, 2015). No detalhamento dos dados serão usadas as letras "G" para se referir ao grupo e "V" a visitante. Os visitantes são numerados de 1 a 4 em cada grupo, sendo o V1 o adolescente que usou a 
câmera. Antes de entrar na exposição, os adolescentes responderam a um questionário para ajudar a traçar seus perfis socioculturais.

Tabela 1 - Relação da faixa etária, gênero, escolaridade e identificação dos visitantes de cada grupo.

\begin{tabular}{|c|c|c|c|c|}
\hline Grupo & Identificação dos visitantes & Escolaridade & Faixa etária & Gênero \\
\hline \multirow[t]{4}{*}{ G1 } & V1 & $9^{\circ}$ ano Ensino Fundamental & 15 anos & Masculino \\
\hline & V2 & $9^{\circ}$ ano Ensino Fundamental & 16 anos & Masculino \\
\hline & V3 & $9^{\circ}$ ano Ensino Fundamental & 14 anos & Feminino \\
\hline & V4 & $9^{\circ}$ ano Ensino Fundamental & 15 anos & Feminino \\
\hline \multirow[t]{4}{*}{ G2 } & V1 & $9^{\circ}$ ano Ensino Fundamental & 15 anos & Masculino \\
\hline & V2 & $9^{\circ}$ ano Ensino Fundamental & 15 anos & Feminino \\
\hline & V3 & $9^{\circ}$ ano Ensino Fundamental & 14 anos & Masculino \\
\hline & V4 & $9^{\circ}$ ano Ensino Fundamental & 14 anos & Feminino \\
\hline \multirow[t]{4}{*}{ G3 } & V1 & $3^{\circ}$ ano Ensino Médio & 17 anos & Feminino \\
\hline & V2 & $3^{\circ}$ ano Ensino Médio & 17 anos & Feminino \\
\hline & V3 & $3^{\circ}$ ano Ensino Médio & 16 anos & Masculino \\
\hline & V4 & $3^{\circ}$ ano Ensino Médio & 17 anos & Masculino \\
\hline \multirow[t]{4}{*}{ G4 } & V1 & $9^{\circ}$ ano Ensino Fundamental & 15 anos & Feminino \\
\hline & V2 & $9^{\circ}$ ano Ensino Fundamental & 14 anos & Feminino \\
\hline & V3 & $5^{\circ}$ ano Ensino Fundamental & 15 anos & Masculino \\
\hline & V4 & $6^{\circ}$ ano Ensino Fundamental & 16 anos & Masculino \\
\hline \multirow[t]{4}{*}{ G5 } & V1 & $1^{\circ}$ ano Ensino Médio & 15 anos & Feminino \\
\hline & V2 & $1^{\circ}$ ano Ensino Médio & 15 anos & Feminino \\
\hline & V3 & $1^{\circ}$ ano Ensino Médio & 15 anos & Masculino \\
\hline & V4 & $1^{\circ}$ ano Ensino Médio & 15 anos & Masculino \\
\hline
\end{tabular}

Fonte: autoria própria.

As visitas, em contexto não escolar e guiadas por mediadores (conforme acontecem tradicionalmente na instituição), foram realizadas em dias úteis nos meses de agosto, outubro e novembro de 2018. Todas as visitas seguiram o mesmo percurso: iniciando no primeiro 
espaço de maior contemplação e leitura, passando pelo segundo mais interativo e terminando com a exibição da reportagem "O uso da tecnologia nos esportes". Nem todos os grupos participantes dessa pesquisa assistiram a reportagem, seja pela falta de tempo, quando a visita já estava se prolongando demais, ou quando os mediadores encerravam a visita antes de passar pelo último espaço sem um motivo explícito para as pesquisadoras.

\section{III.2 Arcabouço teórico e categorias de análise}

Neste artigo, utilizaremos como ferramenta de análise um protocolo de categorização de vídeos que foi, inicialmente, construído a partir de uma adaptação de um modelo proposto pelo grupo de pesquisa canadense GREM (em francês, Groupe de recherche sur l'éducation et les musées), que se baseia no triângulo pedagógico proposto por Renald Legendre para adequá-lo às experiências vividas no contexto dos museus (VILLEGAS, 2012; ALLARD et $a l .$, 1998). Ele foi escolhido por ser útil para analisar a forma como as experiências são organizadas no museu, já que traz as relações entre três atores fundamentais em uma visita a um museu: os módulos expositivos/temas, os mediadores e os visitantes. A partir desse estudo e outros referenciais teóricos pesquisadores e profissionais de alguns museus e centros de ciências da rede de pesquisa criaram um protocolo de análise para serem utilizadas nos estudos do "O Olhar do Visitante" (MASSARANI et al., 2019a, 2019b, 2019c, 2019d)

Os vídeos obtidos pela gravação da câmera foram colocados no software Dedoose 8.0.23 para ser codificados.

O protocolo de análise é dividido em cinco dimensões: Conversas, Tipos de interação, Fotos, Mudança e Emoção; sendo as duas primeiras subdivididas, como é possível ver nas Tabelas 2, 3 e 4, que seguem:

Tabela 2 - Primeira dimensão das categorias de análise de pesquisa.

\section{Conteúdo das conversações}

Conversas sobre temas de Diálogos sobre algum tema científico discutem dilemas éticos e morais da ciência ciência, impacto social da atividade científica, trazem dados ou conteúdos científicos, questões sobre a atuação profissional ou vida pessoal e aparência de cientistas.

Conversas sobre a Diálogos sobre temáticas abordadas pela exposição que não são de conteúdos exposição e temática não científicos, por exemplo, que abordam temas relacionados à cultura que vão além científica da ciência.

Conversas sobre exposição Diálogo desencadeado a partir da interação dos visitantes com a exposição e/ou (funcionamento, design, experiência museal) os módulos expositivos, seja sobre seu funcionamento, design e/ou experiência museal

Conversas não relacionadas ao conteúdo da exposição

Abordagem de temas não relacionados diretamente à visita ou temáticas que tangenciam.

Associações

com Mobilização, utilização, questionamento sobre, seus próprios conhecimentos, experiências anteriores e crenças, rituais, modos de vida, na experiência museal, fazendo referência a 
Fonte: Massarani et al. (2019a, 2019b, 2019c, 2019d).

Já em relação às interações que ocorrem nas exposições, elas podem ser de três tipos: entre o visitante e o módulo expositivo, entre o visitante e o mediador e entre os visitantes (Tabela 3).

Tabela 3 - Subcategorias da primeira dimensão das categorias de análise de pesquisa.

\section{Conversas a partir da interação}

Visitante-módulo Diálogo desencadeado a partir da interação dos visitantes com o módulo expositivo. expositivo

Visitante-

Diálogos estabelecidos entre os visitantes e mediadores ou quando os visitantes escutam as mediador orientações e informações do mediador, independentemente, do conteúdo dessa conversa, podendo ser, sobre temáticas da exposição, temas que tangenciam, orientações sobre a visita e experiência museal ou não.

Visitante- Diálogos estabelecidos entre os visitantes, independentemente, do seu conteúdo, ou seja, visitante temáticas da exposição, temas que tangenciam ou não.

Fonte: Massarani et al. (2019a, 2019b, 2019c, 2019d).

A atividade interativa entre o visitante e o módulo expositivo foi subdividida em: atividade interativa e interação contemplativa (Tabela 4).

Tabela 4 - Segunda dimensão das categorias de análise de pesquisa.

Interação Visitante - módulo expositivo

Atividade interativa A interação se dá pela: imersão; experimentação; interação física (apertar botões, girar manivelas, etc.) necessárias para a continuidade da narrativa/enredo/conteúdo do módulo; controle de variáveis e interferência no resultado final/produto do módulo; e/ou jogo.

Interação Contemplação, observação, visualização sem toque/manipulação de um módulo contemplativa expositivo ou parte dele específico.

Fonte: Massarani et al. (2019a, 2019b, 2019c, 2019d).

Neste artigo, faremos uma análise qualitativa dos dados. Entretanto, pelo fato de nosso protocolo de análise apresentar diversas categorias, optamos por nos aprofundar naquelas que tiveram maior ocorrência. 


\section{Resultados}

\section{IV.1 Questionário pré-visita}

No questionário aplicado antes da realização da visita, perguntamos se os adolescentes se interessavam por matérias de ciência e tecnologia na escola. Apenas três participantes declararam não ter interesse. Destes, apenas dois explicaram suas escolhas com as seguintes respostas: "sei lá" e "porque eu sou muito ruim e também faço mais bagunça que deve". Dos 17 que mencionaram interesse por esses temas, justificaram sua resposta com frases do tipo: "Porque é interessante estudar sobre a vida", "Ciência está em tudo", "Acho interessante conhecer a dimensão do campo tecnológico e seu desenvolvimento", "Porque a maneira como as coisas funcionam me instiga", "Porque envolve o avanço tecnológico", "Porque curto bastante e tenho interesse em ter uma futura profissão na área de química". A maior parte dos adolescentes, 14, afirmaram fazer atividades extracurriculares, sendo três delas, atividades esportivas, como, futebol, jiu-jítsu e vôlei. As outras atividades citadas foram: informática, curso preparatório militar, pré-vestibular, trabalho, musicista em orquestra, curso de piano e violoncelo, teatro e desenho, dança, aula de música, curso de inglês.

Sobre as atividades realizadas com a família nos últimos doze meses, "passear no shopping com amigos e família" foi a opção que mais apareceu dentre as respostas (19), seguida de "ir ao cinema" (16) e "participar de festas populares e carnaval" (14). "Visitar museus e centros culturais" foi a opção com menor frequência (5) seguida de "ir ao teatro, ao circo ou espetáculo de dança" e "visitar feiras e exposições artesanais" (6), o que demonstra que a prática de ir a exposições ainda não está incorporada no cotidiano desse público.

\section{IV.2 Análise das visitas}

As visitas de cada grupo duraram em média uma hora, totalizando 5 horas e 36 minutos de gravações dos cinco grupos, com o total de 996 códigos aplicados, sendo que mais de um código pode ser aplicado em um mesmo trecho de vídeo. Dentre os tipos de interações, a que aconteceu entre os visitantes e os mediadores apareceram em maior número de trechos (161 codificações, ocorrendo em 4 horas e 4 minutos). Já a interação entre os próprios visitantes ocorreu em menor número (113, em 2 horas e 8 minutos). Na interação dos visitantes com os módulos expositivos, a interação contemplativa apareceu mais vezes (88 ocorrências, em 1 hora e 21 minutos), porém com o tempo total inferior a atividade interativa (71 ocorrências, em 1 hora e 58 minutos) (Tabela 5). Menor ainda foi a leitura de painel, texto ou foto explicativos (50 ocorrências, em 9 minutos). 
Tabela 5 - Códigos e tempo de duração de cada tipo de Interação.

\begin{tabular}{llcc}
\hline Tipos de Interação & Trechos & Tempo \\
\hline Interação visitante-mediador & & 161 & $4 \mathrm{~h} 4 \mathrm{~min}$ \\
Interação visitante-visitante & & 113 & $2 \mathrm{~h} 8 \mathrm{~min}$ \\
Visitante-módulo expositivo & Atividade interativa & 71 & $1 \mathrm{~h} 58 \mathrm{~min}$ \\
& Interação contemplativa & 88 & $1 \mathrm{~h} 21 \mathrm{~min}$ \\
& Leitura de painel/texto/foto explicativos & 50 & $9 \mathrm{~min}$ \\
\hline
\end{tabular}

Fonte: autoria própria.

Dentro do código "conversas", a categoria "associações com experiências anteriores e vivência pessoal" (114) foi a que apareceu com maior frequência em relação a quantidade de trechos marcados, seguida de "Conversas sobre a exposição e temática não científica" (103), "Conversas sobre a exposição (funcionamento, design, experiência museal)" (90) e “Conversas sobre temas de ciências" (89) aparecendo em menor número (Tabela 6).

Tabela 6 - Códigos e tempo de duração das conversas.

\begin{tabular}{lcc}
\hline Código & Trechos & Tempo \\
\hline Conversas sobre temas de ciências & 89 & $1 \mathrm{~h} 54 \mathrm{~min}$ \\
Conversas sobre a exposição e temática não científica & 103 & $1 \mathrm{~h} 23 \mathrm{~min}$ \\
Associações com experiências anteriores e vivência pessoal & 114 & $51 \mathrm{~min}$ \\
$\begin{array}{l}\text { Conversas sobre exposição (funcionamento, design, experiência } \\
\text { museal) }\end{array}$ & 90 & $57 \mathrm{~min}$ \\
\begin{tabular}{l} 
Conversas não relacionadas ao conteúdo da exposição \\
\hline
\end{tabular}
\end{tabular}

Fonte: autoria própria.

Em relação ao tempo de duração das conversas, as categorias que tiveram uma expressão significativa foram: "conversas sobre temas de ciências" obtendo 1 hora e 54 minutos (89 trechos), "conversas sobre a exposição e temática não científica” com 1 hora e 23 minutos (103 trechos), "conversas sobre exposição (funcionamento, design, experiência museal)" com 57 minutos (90 trechos) e "conversas que os visitantes fazem associação com experiências anteriores e vivência pessoal" somando 51 minutos (114 trechos) (Tabela 6). No tópico seguinte, detalhamos e ilustramos as categorias que tiveram maior representatividade dentro do código de conversas. 


\section{IV.2.1 Conversas sobre temas de ciências}

O código com maior expressão durante as visitas foi "conversas sobre temas de ciências" (com 89 trechos marcados, totalizando 1 h 54 min). Na análise da coocorrência dos códigos (quando dois códigos eram marcados no mesmo intervalo de tempo) esta categoria apareceu junto com a categoria "visitante-mediador" em 73 trechos, enquanto em apenas 19 trechos este código ficou ligado à categoria "visitante-visitante" (Tabela 7).

Tabela 7 - Coocorrência com o código "conversas sobre temas de ciências".

\begin{tabular}{lc}
\hline Códigos & Conversas sobre temas de ciências \\
\hline Visitante-Mediador & 73 \\
Visitante-Visitante & 19 \\
Atividade Interativa & 18 \\
Interação Contemplativa & 40 \\
$\begin{array}{l}\text { Associações com experiências } \\
\text { pessoal }\end{array}$ & 35 \\
\hline
\end{tabular}

Fonte: autoria própria.

Esse resultado nos mostra que conversas relacionadas a temáticas científicas aconteceram com maior frequência entre mediador e visitantes. Como pode ser observado nos exemplos a seguir grande parte dessa interação se deu de modo unidirecional, do mediador para o visitante, com pouco espaço para o diálogo e as trocas com os adolescentes. Notamos também que isso ocorreu não só na primeira parte da exposição, composta por painéis e em que a interação contemplativa se deu com maior frequência, mas também em momentos de atividades interativas. Outra característica observada na interação mediador-visitante é o uso de associações e experiências anteriores para contextualizar o conhecimento divulgado.

Assim, na primeira parte da exposição, os mediadores ${ }^{3}$ explicam a primeira Lei de Newton diante de painéis e os exemplos ilustram atitudes recorrentes nessa parte do circuito da exposição: a mediação do museu fornecia explicações sobre a temática científica, em alguns casos associando a questões do cotidiano, enquanto os visitantes prestavam atenção de forma contemplativa. Esse fato foi recorrente em grande parte do percurso dos adolescentes na exposição, especialmente, quando o código "conversas sobre temáticas científicas" estava relacionado ao código "interação contemplativa" - 40 trechos foram identificados. Para ilustrar, trazemos o trecho a seguir (ex. 1):

\footnotetext{
${ }^{3}$ A letra "M" será utilizada para abordar a fala dos mediadores nos exemplos abordados no texto.
} 
Ex. 1: M:[...] Para falar um pouquinho da primeira Lei de Newton, é quando a gente tem a soma das forças sobre um corpo e isso é zero, e um corpo ele tende a permanecer em repouso, está parado, e em movimento quando está se movendo./ V2: Movimento uniforme, né?/ M: Sim, bom.. aonde que a gente aplica essa primeira Lei de Newton? Por exemplo, num drible de futebol, a gente consegue explicar quando um jogador ele finge que vai numa direção e a tendência do corpo dele quando ele faz esse drible é ele manter o movimento dele. Então, ele andando, ele vai tender a ir para esse lado que ele está indo (...) (G3).

No diálogo do grupo 3 (ex.1) observamos como a interação mediador-visitante acontece de forma unidirecional, com pouca participação dos jovens. Após esse trecho transcrito, a mediadora terminou a explicação lendo uma frase dita por Newton, escrita no painel, "pra mim nunca houve maior fonte de honra ou distinção terrena do que estar ligado aos avanços da ciência" e seguiu para o próximo módulo com os visitantes sem estimular discussão sobre o que foi abordado.

Atitude similar acontece no próximo exemplo (ex.2), em que outro mediador explica para o grupo 4 a primeira Lei de Newton diante do painel expositivo. Assim como no exemplo anterior, o mediador detém a maior parte da fala.

Ex. 2: M: A primeira coisa que a gente vai ver é a primeira Lei de Newton, o nome dela é Inércia. Mas ela também é chamada de movimento e repouso, é um nome bem sugestivo. Porque ela diz [...] que o que está em movimento continua em movimento e o que está parado continua parado, até que alguma coisa mude isso. Como que a gente vê isso no nosso dia-a-dia? Vocês andam de ônibus? Vocês vão para a escola de ônibus, alguma coisa assim? /Visitantes: Sim!/ M: [...] Já aconteceu de vocês andarem de ônibus e o ônibus dá aquele freiadão? /Visitantes: Sim!/ M: E o que acontece com vocês?/ V2: Eu vou para frente./ M: Por que você vai pra frente? Por que você acha que vai pra frente?/ V2: Porque o ônibus está andando e do nada ele pára, aí eu vou para frente. (G4)

Após esse trecho, a mediadora seguiu explicando a Lei da Inércia utilizando alguns exemplos como o drible do futebol e a corrida do atletismo. Ao final da explicação ela perguntou se os visitantes tinham alguma dúvida, e com a resposta negativa, eles seguiram para o próximo painel. Como podemos ver, apesar de o mediador tentar instigar os visitantes com perguntas, não houve uma discussão sobre o assunto. A dinâmica ficou apenas em perguntas e respostas curtas, sem uma reflexão aprofundada e crítica sobre o conteúdo.

Pudemos observar que a comunicação de forma unilateral acontece não só quando há a interação contemplativa. Isso também aconteceu na coocorrência do código "conversas sobre temáticas científicas" com "atividade interativa" - marcados em 18 trechos. No exemplo 3, a seguir, o mediador explica os conceitos físicos da atividade interativa "cadeira giratória", que é a simulação do giro que as ginastas olímpicas fazem. Enquanto a visitante estava sentada na cadeira (Fig. 1), o mediador forneceu uma força para que a cadeira girasse. Então ele pediu para que ela abrisse os braços e pernas e depois os fechassem para que eles 
percebessem a diferença na velocidade do giro da cadeira. Após participarem da atividade, os visitantes passaram para o próximo módulo interativo.

Ex. 3: M: Esse experimento é chamado de giro da bailarina. Ele é o quê? A teoria física diz o que? Que quanto mais você conserva massa num ponto, mais você contrai a sua massa, mais rápido você gira. E quanto mais você abre seu ponto... assim... da massa, mais devagar você vai girar./ V1: Você pode dar um exemplo aí? / M: Ah, já que você pediu então senta aqui, ou pode ser qualquer um! [mediador aponta para a cadeira giratória]./ V3: Igual a bola de futebol [faz movimento de giro com as mãos]./ M: Ah eh, e por exemplo, vamos dar um exemplo no esporte. Tu vê a Daiane dos Santos, a da ginástica, toda vez que ela vai saltar, ela encolhe totalmente o corpo e gira./ V1: E depois ela se joga!/ M: E aí cai. (G5)

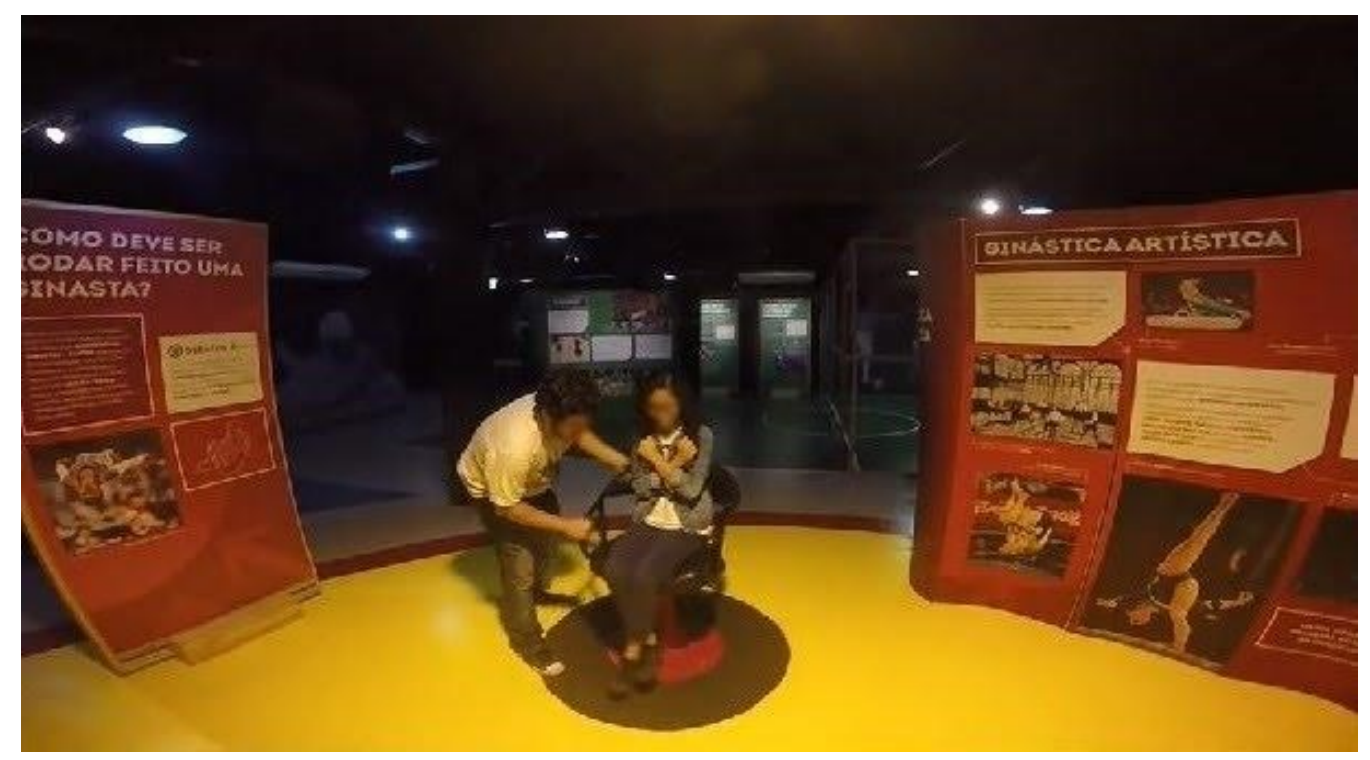

Fig. 1 - Imagem da atividade interativa cadeira giratória.

Outro aspecto relevante na interação mediador-visitante é a coocorrência dos códigos "conversas sobre temas de ciências" e "associação com experiências anteriores", identificados em 35 trechos. Observamos que os mediadores trouxeram exemplos das experiências de suas vidas e dos visitantes para contextualizar e explicar o conteúdo da exposição. Um exemplo para ilustrar é o que aconteceu com o grupo 4. Logo após dois visitantes realizarem a atividade interativa da pista de corrida - em que eles tiveram que correr uma distância com o tempo cronometrado (Fig. 2) - a mediadora fez um comentário relacionando o tempo realizado pelos adolescentes com o do atleta jamaicano Usain Bolt:

Ex. 4: M: Vocêfez metade do tempo que o Bolt faz numa pista dez vezes o tamanho dessa. (G4)

Após esse comentário, a mediadora perguntou aos visitantes qual foi a maior dificuldade durante a corrida, e eles responderam que foi a parada por causa da velocidade. A 
mediadora aproveitou essa resposta e explicou que essa dificuldade de parada estava relacionada à grande aceleração que eles estavam (Ex. 5).

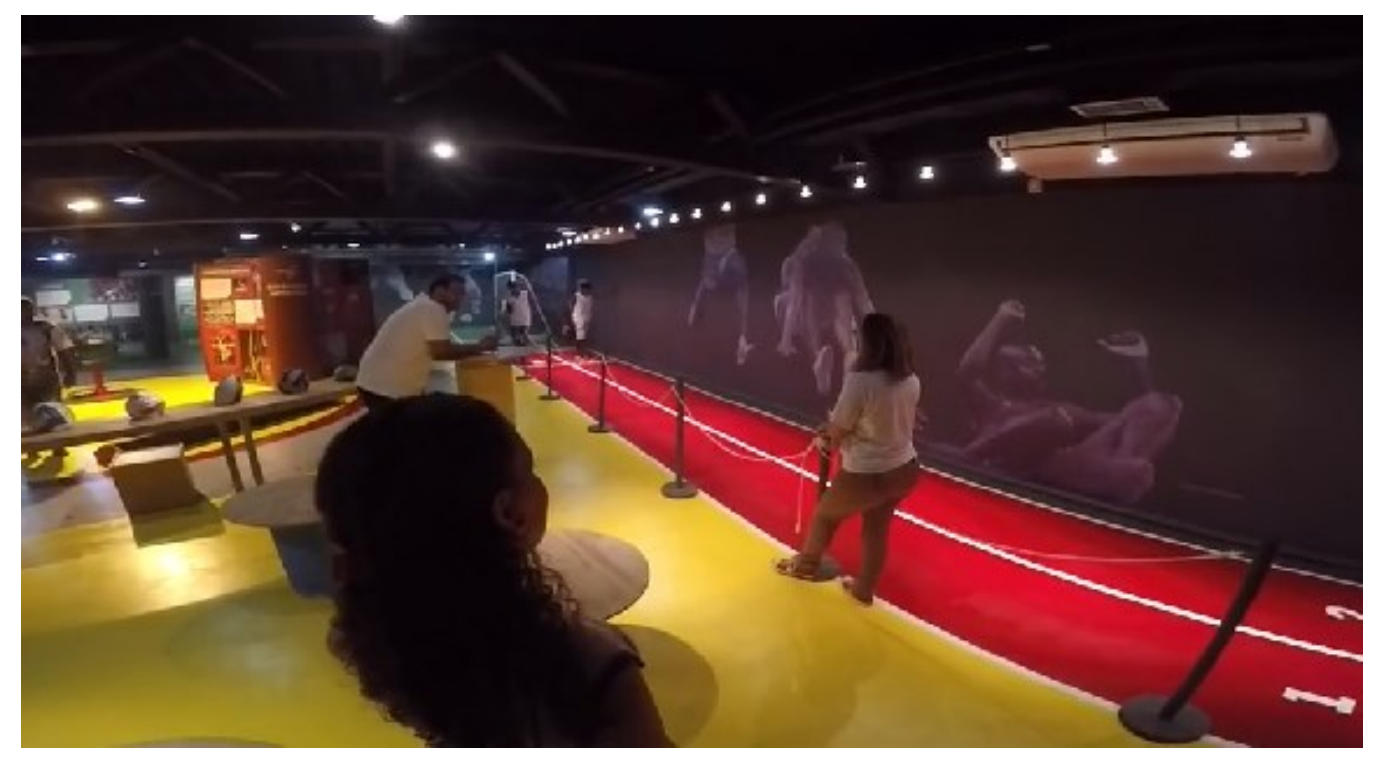

Fig. 2 - Imagem da atividade interativa pista de corrida.

Ex. 5: M: Me diz uma coisa, pra vocês na hora de parar aí no final, foi fácil ou foi difícil?/ V3: Foi difícil./ M: Por que foi dificil?/ V3: Foi difícil por causa da velocidade./ M: Muito bem! Vocês estavam com uma aceleração muito grande. Quando vocês fizeram mais força? Na partida ou na chegada?/ V4: Na chegada./ M: Na chegada? Por que? [Os visitantes ficam em silêncio] /M2: (...) lembra que ela [a outra mediadora] falou sobre o onibus pra vocês? Quando você está em movimento é muito mais difícil você parar o seu movimento... (G4)

Com esses exemplos fica evidente que, na nossa análise, notamos que as conversas sobre temáticas científicas aconteceram com maior frequência quando havia a participação do mediador, ou seja, explicando temas de ciências. Os adolescentes raramente comentavam algo sobre ciência entre si, identificado em apenas 19 trechos. O exemplo 6 é um dos poucos momentos identificados em que há trocas entre os próprios visitantes durante a explicação do mediador sobre a segunda Lei de Newton.

Ex. 6: M: (...) O que é massa?/ V3: Que ocupa um lugar no espaço./ V1:Bater uma massa/ M: É o que?/V1: Bater uma massa é quando dois corpos./ M [para V3]: Você falou uma coisa interessante./ V3: Eu?/ M: É. O que é a definição de matéria... o que ocupa um lugar no espaço./ V3: Ah, sim! Mediador: "Massa é a quantidade de...?” V1: “Ah, caramba! O professor Thiago falou mas esqueci!” Mediador: "Mas ela falou a palavra ali certinho!" V2: "Fala de novo V3!" V1: "Fala garota!” Mediador: "Foi um impulso... que você falou assim...” (...) V3: “matéria é o que ocupa um lugar no espaço, não é?” (...) (G2). 
Em seguida o mediador seguiu explicando o conceito de massa e aceleração, fazendo algumas perguntas aos visitantes para saber se eles conhecem as definições, e depois foram para o próximo módulo expositivo.

\section{IV.2.2 Conversas sobre a exposição e temática não científica e sobre a exposição}

$\mathrm{Na}$ análise da coocorrência do código "conversas sobre a exposição e temática não científica", este código aparece mais vezes associado a "atividades interativas" em 41 trechos do que a "interação contemplativa" em 18 trechos (Tabela 8). Essa informação revela - além de que esse tipo de conversa aconteceu mais vezes no segundo momento da exposição, em que existiam mais atividades interativas - que as atividades interativas despertaram conversas que não estavam diretamente relacionadas a temáticas de alguma área do conhecimento científico, mas que ainda assim eram relacionadas à exposição e sua temática, ou seja, esportes.

Tabela 8 - Coocorrência com o código "conversas sobre a exposição e temática não científica".

\begin{tabular}{lc}
\hline Códigos & $\begin{array}{c}\text { Conversas sobre a exposição e } \\
\text { temática não científica }\end{array}$ \\
\hline Visitante-Mediador & 53 \\
Visitante-Visitante & 46 \\
Atividade Interativa & 41 \\
Interação Contemplativa & 19 \\
Associações com experiências anteriores e vivência pessoal & 14 \\
\hline
\end{tabular}

Fonte: autoria própria.

No exemplo 7, podemos ver uma conversa que aconteceu ainda no primeiro espaço da exposição, quando os visitantes já estavam se encaminhando para o segundo local. Um deles observou uma das camisas expostas e perguntou ao mediador:

Ex. 7: V2: Essa camisa aqui autografada também é brasileira?/ M: É, algumas estão! Essa aí é de vôlei. /V3: Elas devem ter ganhado, né?/ M: Mas mesmo que não, a seleção de vôlei sempre esteve muito em alta, né!/ V1: É o quê? Feminino?/M: É... agora está um pouco menos, mas sempre esteve em alta! E essa seleção aqui com a Sassá, a camisa é da Sassá, acabei de ver aqui.../V4: Carol, Nathália./V1: Maiara. (G5) 
Outro exemplo que ilustra as conversas de temática não científica ao longo da exposição é o que aconteceu durante a atividade do futebol de cinco (ex. 8). Um dos visitantes estava com os olhos vendados no canto esquerdo da quadra e o mediador colocava a bola em seus pés para que ele chutasse a gol. $\mathrm{O}$ gol era tapado com o desenho de um goleiro na frente e com apenas alguns buracos para que a pessoa acertasse e fizesse o gol. Atrás do gol estava outro adolescente falando alto para que o visitante vendado pudesse escutar e chutar na direção do som.

Ex. 8: V2: O gol está aqui!/ M [para V1]: Coloquei a bola na sua frente./ V2: O gol está aqui!/ M [para V1]: Quer que coloque a bola mais para a frente?/V1: Não, eu quero só segurar ela pra poder encostar nela... ela parou?/ M: Parou!/ V2: O gol está aqui!/ V1: Aonde? Grita mais alto!/ V2: O gol está aqui! No alto! [V1 chuta a bola para o gol e não acerta] Ih... passou bem longe!/ M: Boa... foi bom (G2).

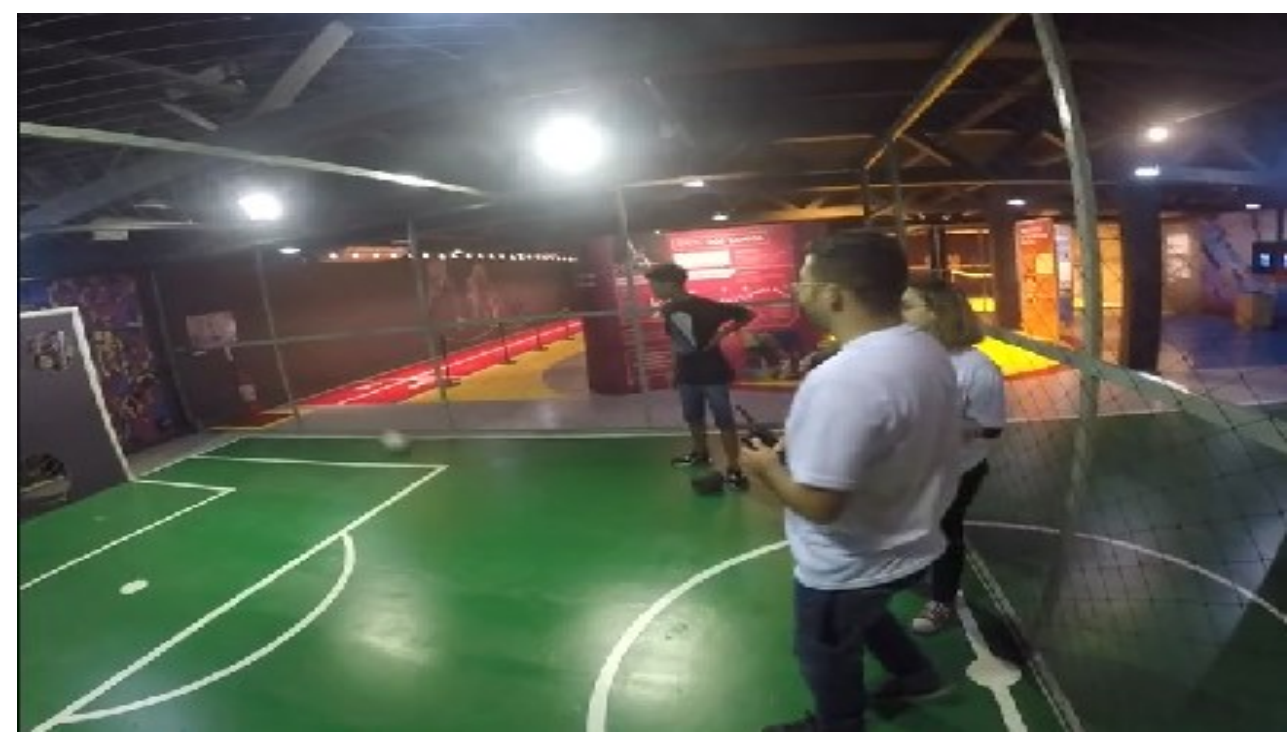

Fig. 3 -Imagem da atividade interativa Futebol de Cinco.

No exemplo 9, observamos outra conversa com temática não científica entre os visitantes. Nesse exemplo, duas meninas do grupo estavam realizando a atividade interativa da mesa de futebol de pregos, disputando uma contra a outra.

Ex. 9: V1: (...) Calma! / V2: Eu não sou muito boa, sabe?! / V1: Vai! / V2: Assim você me deixa nervosa! (...) Não! Essa é minha área! / V1: Ah, sorry! (...) O normal deve ser fazer gol por aqui né? [aponta para o local onde o gol é feito] V1: Pô, destruiu meu bonequinho. / V2: Desculpa! (...) (G5).

O código "conversas sobre exposição (funcionamento, design, experiência museal)" apareceu fortemente associado à interação "visitante-mediador" em 64 trechos, em 30 trechos "visitante-visitante" e em 28 com "atividade interativa" (Tabela 9). Isso nos mostra que essa categoria de conversa acontecia mais vezes quando o mediador explicava o funcionamento 
das atividades interativas e a estrutura da exposição, mas também ocorreu na interação visitante-visitante e durante as atividades interativas.

Tabela 9 - Coocorrência com o código "conversas sobre a exposição (funcionamento, design, experiência museal)".

\begin{tabular}{lc}
\hline Códigos & $\begin{array}{c}\text { Conversas sobre a exposição (funcionamento, design, } \\
\text { experiência museal) }\end{array}$ \\
\hline Visitante-Mediador & 64 \\
Visitante-Visitante & 30 \\
Atividade Interativa & 28 \\
Interação Contemplativa & 13 \\
\end{tabular}

Fonte: autoria própria.

Para ilustrar como essas conversas aconteceram, no exemplo 10, observamos o mediador explicando como realizar a atividade da trave olímpica, atravessando ele mesmo por ela. Nesse exemplo, notamos dois códigos coocorrendo com as conversas sobre a exposição: interação "visitante-mediador" e "atividade interativa".

Ex. 10: M: (...) Isso aqui é uma trave de equilíbrio, você tem que passar por todo ela sem que você caia. Esse é considerado o mais fácil de todos, depois da corrida e da natação, acho que esse é o mais fácil./V1: Fácil? Fácil porque a trave está aqui... botar ele em altura.../ M: Lógico que ia ser muito mais díficil, né? (G1)

O mesmo acontece no exemplo 11: a visitante, ao olhar para um painel explicativo sobre atletismo, perguntou para que serve o bloco de largada presente nas provas de corrida. A mediadora explicou brevemente sua função.

Ex. 11: V1: O que interfere na pessoa de ela ficar assim... precisando desse negocinho?/ M: Ah, esse bloco de largada tem lá. Vocês podem até fazer, correr inclusive. Isso ai é pra um impulso na hora que eles forem iniciar a corrida. Mas eu vou lá mostrar pra vocês, porque vocês correndo acho que fica mais claro de vocês entenderem. (G3)

Por fim, o código "conversas sobre exposição (funcionamento, design, experiência museal)" foi associado a "visitante-visitante" em 30 trechos, nos quais pudemos perceber um maior protagonismo dos visitantes que falavam entre si sobre o funcionamento das atividades interativas. No exemplo a seguir, vemos o diálogo que aconteceu na trave olímpica, onde os visitantes tentavam fazer um salto do tipo estrelinha, onde a V1 tenta ensinar ao V3 como executá-lo de maneira correta. 
Ex. 12: V1 [para V3]: (...) Não, com a mão tá!? / [V3 faz a estrelinha] / V1 [para V3]: É assim mesmo! / V3 [para V1]: Eu tenho medo de cair. / V2 [para V3]: Tá quase lá! / V3 [para V1]: Vai, dá mortal! / [V1 faz a estrelinha] / V1 [para V3]: Certinho, né? Você viu? Foi bem ali mesmo. / V4: Olha, tem futebol de moeda! / V1: É o que? Golzinho? (...) (G3).

\section{Discussão e considerações finais}

Com os resultados, vimos que a maioria dos adolescentes que participaram de nosso estudo (17 entre os 20) declararam ter interesse em disciplinas que envolviam ciência e tecnologia e três deles realizavam algum esporte como atividade extracurricular, o que nos mostra que esses jovens potencialmente já tinham um interesse prévio no tema abordado pela exposição. Vimos, também, que apenas alguns (6) dos adolescentes que participaram de nosso estudo tinham visitado museus e centros culturais nos doze meses anteriores à pesquisa dado que corrobora a pesquisa desenvolvida pelo INCT-CTCP (MASSARANI et al., 2019), na qual apenas $6 \%$ dos jovens afirmaram ter visitado algum museu de ciência ou centro de ciência no último ano. Somado a isso, nossos dados também estão em consonância com os hábitos culturais do caxiense (LEIVA, 2014) e demonstram que o perfil de pouco acesso a museus também ocorre em outras cidades da Baixada Fluminense, Belford Roxo e São João de Meriti, em que uma parte dos participantes da pesquisa residiam.

Durante a visitação à exposição estudada e tendo como base o modelo proposto que sistematiza as experiências que acontecem em um museu em três esferas (visitante-visitante; visitante-mediador e visitante-módulo expositivo) (VILLEGAS, 2012; ALLARD et al., 1998), observamos que a interação dos visitantes com os mediadores prevaleceu à interação dos visitantes entre si. Dessa forma, notamos que, na experiência desses adolescentes, prevaleceram as relações de transposição retratadas nas explicações e conversas que os mediadores incitaram durante a visita, sendo mais reduzidas as relações de apropriação por parte dos jovens, isto é, a interpretação direta feita pelos visitantes do conteúdo proposto pelo museu. Esses dados podem estar relacionados à própria proposta da exposição de ser totalmente guiada pelos mediadores - cultura fortemente fomentada nos museus de ciência brasileiros que apostam na mediação para possibilitar diferentes modos de aprender no contexto museal (MARANDINO, 2008).

A importância dos mediadores em museus de ciência tem sido destacada por profissionais que atuam em museus de ciência e por pesquisadores da área. Alguns autores (GARCIA, 2006; SÁPIRAS, 2007) destacam que a presença do mediador fornece ao museu um maior controle sobre o discurso expositivo pretendido, reforçando a importância desse profissional no processo de aprendizagem. Outro estudo no museu de ciência Maloka, na Colômbia, demonstrou que a presença dos mediadores parece ter levado a um maior refinamento e complexificação da construção de sentido por parte dos adolescentes (MASSARANI et al., 2019c). Os mediadores estimularam os adolescentes a mobilizar 
conhecimentos prévios em relação aos conteúdos da exposição, o que em alguma medida também foi observado no presente estudo. No entanto, como efeito colateral, observamos um protagonismo reduzido por parte dos adolescentes deste estudo, na escolha dos percursos e conversas ao longo da visita.

No que diz respeito aos conteúdos das conversas, aquelas voltadas para a temática científica foram as que tiveram o maior tempo registrado (1h e $54 \mathrm{~min}$.). Essas conversas aconteceram, na grande maioria das vezes, entre os mediadores e visitantes - e poucas vezes apenas entre os visitantes. Assim, os mediadores foram os protagonistas das conversas, muitas vezes abordando os conteúdos da exposição de forma unidirecional, no chamado modelo de déficit, em que um especialista (no caso, o mediador) explicava conceitos científicos para um não especialista (no caso, os adolescentes). Divulgadores da ciência, contudo, têm defendido a relevância de se adotar em espaços de educação não formal - como são os museus de ciência - modelos que permitem que os visitantes acionem seus próprios conhecimentos e experiências prévios e que a relação entre especialistas e não especialistas aconteçam de forma horizontal proporcionando trocas de saberes e diálogo (BROSSARD; LEWENSTEIN, 2009). Do ponto de vista da educação em museus, podemos considerar que esse modo de mediar se localiza na interseção do que especialistas identificam como "visita-palestra" - em que há um aprofundamento de um tema e baixo nível interacional - e como "discussão dirigida" - em que a mediação se faz por meio de questionamentos, de forma a facilitar a troca de saberes e a mobilização de conhecimento pertinentes àquela exposição (MARANDINO, 2008; GRINDER, 1985). Para que essa discussão dirigida em uma exposição seja bem-sucedida, contudo, é necessário a participação do público e, mais que isso, que o mediador construa uma estrutura discursiva que lhe auxilie a fazer boas perguntas para fomentar boas discussões - artifício que apareceu de forma superficial e em poucos momentos nos dados coletados.

Um aspecto que reforça o papel importante do mediador na exposição foi o alto grau de coocorrências das conversas sobre temáticas científicas com conversas sobre experiências anteriores e vivência pessoal. Isso fica em evidência particularmente quando os mediadores utilizavam experiências de suas vidas e dos adolescentes para contextualizar e explicar os conceitos da exposição. Por exemplo, para abordar a inércia, a maioria dos mediadores utilizava o exemplo do ônibus, perguntado aos visitantes se eles tinham o hábito de andar de ônibus e se já vivenciaram uma situação de freada brusca. Os visitantes também traziam nomes de atletas e suas experiências praticando alguns esportes quando os mediadores os questionavam durante a visita. Nesse sentido, Yalowitz (2015) enfatiza que percepções prévias e origens socioculturais do visitante induzem fortemente a aprendizagem na visita, se relacionando também com seus interesses individuais e motivações.

Ainda associado ao trabalho de mediação, as conversas relacionadas ao funcionamento, design e experiência museal da exposição também estiveram associadas em maior número com a relação visitante-mediador. Esses dados revelam que esse tipo de 
conversa aconteceu quando o mediador explicava o funcionamento das atividades interativas. De maneira geral, não surpreendentemente, a interação entre os próprios adolescentes aconteceu com maior frequência no espaço em que tinham atividades interativas. Nesse local, os visitantes tiveram uma liberdade maior para interagir entre si, com menor influência dos mediadores mesmo eles estando presentes o tempo todo. No entanto, vale ressaltar que essa interação gerou pouca conversa sobre as temáticas científicas: os adolescentes falaram mais sobre as atividades que estavam fazendo, suas regras e execução.

Por essas razões, podemos afirmar que a presença e abordagem do mediador tiveram impacto na interação dos adolescentes com seus pares, refletindo na baixa interação exclusivamente entre eles - fator que na literatura (MASSARANI et al., 2019c) é considerado benéfico para os processos de divulgação e apropriação de temáticas científicas. Isso porque o grupo de visitantes amigos compartilha contextos sociais e culturais comuns e é por meio das conversas que eles criam novas relações de conhecimentos nas quais surgem reflexões de diversos tipos, desde associações a aspectos sociais até o conhecimento disciplinar das ciências, retratando a natureza social e reflexões interdisciplinares presentes na experiência de visita ao museu.

A visita à exposição pode proporcionar a experimentação dos conceitos vistos previamente no contexto escolar potencializando sua apropriação, bem como ampliando as relações com o contexto pessoal de cada um. Nesse sentido, vale destacar que o papel do mediador em nosso estudo teve também aspectos positivos: enquanto por vezes dominava as conversas, em outros casos mantiveram uma de suas principais tarefas desse profissional de museus, que é mover o visitante de um estado de relativo conforto cognitivo, por meio de desafios, conscientização, curiosidade ou provocação, para engajá-los na apropriação de conhecimentos ofertados pelo museu (GOOD, 2013).

Nesse sentido, Falk e Dierking (2000) e Roschelle (1995) argumentam que os museus de ciências interativos são espaços onde é possível associar teoria e prática, conectando os fenômenos científicos e conceitos específicos às atividades, objetos e exposições através de uma forma alternativa ao ensino escolar, sendo potencialmente mais sensível aos interesses e necessidades dos jovens. De fato, nossos dados sinalizam que a exposição "Movimente-se! A física dos esportes" conseguiu, em grande medida e fomentado pelos mediadores, mobilizar os adolescentes em torno de temas de ciência - e a escolha do tema "esportes" parece ter ajudado nesse sentido. Nossos resultados indicam que a exposição conseguiu desencadear conversas entre mediadores e visitantes sobre a temática, demonstrando que existem modos diversos de se trabalhar conteúdos de física de forma lúdica e interativa com adolescentes potencializando a apropriação de conceitos e conhecimentos. Afinal, como Almeida e Silva (2015, p. 1) argumentam "associar aspectos da prática dos esportes aos respectivos conceitos físicos pode se tornar um caminho lúdico e útil não só para despertar o interesse pelo ensino de física, mas também para facilitar o aprendizado dessa disciplina". 
Por fim, vale destacar que a presente pesquisa fornece alguns subsídios para reflexão a respeito dos modos de mediar em museus de ciências. Se, por um lado, as visitas totalmente mediadas são comuns nos museus brasileiros e possuem fins educacionais, por outro, ainda existem desafios a serem explorados em estudos futuros e em práticas de formação de mediadores. Afinal, como fomentar uma discussão sobre os conteúdos de ciência, fazendo boas perguntas, sem que a visita se torne uma palestra, uma transposição da sala de aula tradicional ou ocorra baseada no modelo déficit? Como unir as conversas sobre ciência com a interação física e as emoções sem cercear as interações entre os próprios adolescentes?

Diferentes aspectos influenciam o hábito de visitação dos museus de ciências, especialmente, quando se trata de regiões com pouca oferta, como é o caso da Baixada Fluminense. Acreditamos que estudos como este não encerram a discussão sobre as relações que visitantes - em especial, adolescentes - estabelecem nesses locais e com esses locais, mas, que são um passo importante para o fomento à cultura de frequentar espaços científicoculturais, uma vez que, além de apontar desafios, busca compreender interesses, conversas, modos de interagir entre eles, com os mediadores e com a exposição.

\section{Agradecimentos}

Este estudo foi realizado no escopo do Instituto Nacional de Comunicação Pública da Ciência e Tecnologia e contou com o apoio da Fundação Carlos Chagas Filho de Amparo à Pesquisa do Estado do Rio de Janeiro (FAPERJ) e do Conselho Nacional de Desenvolvimento Científico e Tecnológico-CNPq. Uma das autoras (Luisa Massarani) agradece pela bolsa produtividade do CNPq; três das autoras agradecem à Faperj respectivamente pelas bolsas Cientista de Nosso Estado, Jovem Cientista de Nosso Estado (Luisa Massarani e Jessica Norberto Rocha) e TCT (Eliza Cabral). Agradecemos ainda o apoio do Museu Ciência e Vida e da Fundação Cecierj para a realização da pesquisa.

\section{Referências bibliográficas}

ALLARD, M.; LAROUCHE, M.; MEUNIER, A.; THIBODEAU, P. Guide de planification et devaluation dês programes éducatifs. Éditions Logiques, 1998.

ALMEIDA, B. S. G.; SILVA, R. C. Aerodinâmica de bolas. Revista Brasileira de Ensino de Física, v. 37, n. 3, p. 3505, 2015.

ALMEIDA, C.; AMORIM, L.; BRITO, F.; FERREIRA, J. R.; MASSARANI, L. (Coord.). Centros e museus de ciência do Brasil 2015. Rio de Janeiro: Associação Brasileira de Centros e Museus de Ciência, UFRJ, Casa da Ciência, Fiocruz. Museu da Vida, 2015. Disponível em: 
$<$ http://www.casadaciencia.ufrj.br/Publicacoes/guia/Files/guiacentrosciencia2015.pdf $>$. Acesso em: 29 jan. 2020.

BASTOS, P. W.; MATTOS, C. R. Esporte: um aliado para o ensino de física. In: $7^{\circ}$ ENCONTRO NACIONAL DE PESQUISA EM EDUCAÇÃO EM CIÊNCIAS, 7, 2009. Florianópolis. Anais...

BERNARD, H. R. Research methods in anthropology: qualitative and quantitative approaches. Lanham, MD: AltaMira Press, 2005.

BIERNARCKI, P.; WALDORF, D. Snowball sampling-problems and techniques of chain referral sampling. Sociological Methods and Research, v. 10, n. 2, 1981.

BROSSARD, D.; LEWENSTEIN, B. A critical appraisal of models of public understanding of science: using practice to inform theory. In: KAHLOR, L. New Agendas in Science Communication. Mahwah: Laurence Erlbaum Publishers, 2009. p. 11-39.

CGEE. Percepção pública da C\&T no Brasil - 2019. Resumo executivo. Brasília, 2019. Disponível em:

$<$ https://www.cgee.org.br/documents/10195/734063/CGEE_resumoexecutivo_Percepcao_pub _CT.pdf $>$. Acesso em: 29 jan. 2020.

DUARTE, M.; OKUNO, E. Física do futebol: mecânica. São Paulo: Oficina de textos, 2012.

FALK, J.; DIERKING, D. Learning from museums: Visitor experiences and the making of meaning. AltaMira Press, 2000.

GARCIA, V. A. R. O processo de aprendizagem no Zoológico de Sorocaba: análise da atividade educativa visita orientada a partir dos objetos biológicos. 2006. Dissertação (Mestrado em Educação) - Faculdade de Educação, Universidade de São Paulo, São Paulo.

GLĂVEANU, V. P.; LAHLOU, S. Through the creator's eyes: Using the subjective camera to study craft creativity. Creativity Research Journal, v. 24, n. 2-3, 2012.

GOOD, L. Unpacking docent practice in free choice science learning settings: A qualitative study documenting thew hat and whys of docent interpretive practice. 2013. Doctoral (Dissertation) - Oregon State University. 
GRINDER, A. L.; MCCOY, E. S. The good guide: a sourcebook for interpreters, docents and tour guides. Scottsdale, Ironwood Press, 1985.

LAHLOU, S. How can we capture the subject's perspective? An evidence-based approach for the social scientist. Social science information, v. 50, n. 3-4, 2011.

LEIVA, J. Cultura em Duque de Caxias. São Paulo - São Paulo, Leiva Cultura \& Esporte, 2014. Disponível em: <http://lurdinha.org/site/wp-content/uploads/habitosculturais duquedecaxias_jleiva_braskem.pdf $>$. Acesso em: 29 jan. 2020.

MARANDINO, M. (Org.). Educação em museus: a mediação em foco. São Paulo: GEENF, Faculdade de Educação, Universidade de São Paulo, 2008.

MARANDINO, M. Ação educativa, aprendizagem e mediação nas visitas aos museus de ciências. In: MASSARANI, L.; ALMEIDA, C. Workshop Sul-Americano \& Escola de Mediação em Museus e Centros Ciência. Rio de Janeiro: Museu da Vida, Casa de Oswaldo Cruz, Fiocruz, 2008.

MASSARANI, L.; CASTELFRANCHI, Y.; FAGUNDES, V.; MOREIRA, I.; MENDES, I. $O$ que os jovens brasileiros pensam da Ciência e da Tecnologia? Resumo executivo, 2019. Disponível em:

$<$ http://www.coc.fiocruz.br/images/PDF/Resumo\%20executivo $\% 20$ survey $\% 20$ jovens_FINA L.pdf>. Acesso em: 23 jul. 2019.

MASSARANI, L.; FAZIO, M. E.; ROCHA, J. N. La interactividad en los museos de ciencias, pivote entre expectativas y empiria: el caso de CICyT Abremate (Argentina). Ciência e Educação, UNESP, v. 25, p. 467-484, 2019a.

MASSARANI, L.; REZNIK, G.; ROCHA, J. N.; FALLA, S.; ROWE, S.; MARTINS, A.; AMORIM, L. A experiência de adolescentes ao visitar um museu de ciência: Um estudo no Museu da Vida. Ensaio: Pesquisa em Educação em Ciências, v. 21, p. 21, e10524, 2019 b.

MASSARANI, L.; ROCHA, J. N.; POENARU, L.; FALLA, S.; ROWE, S. Adolescents learning with exhibits and explainers: The case of Maloka'. International Journal of Science Education, v. 2, p. 1-15, 2019c.

MASSARANI, L.; CHAGAS, C.; ROCHA, L.; ROWE, S.; FONTANETTO, R. Children's protagonism in a science exhibition: an exploratory study of an exhibition in Rio de Janeiro (Brazil). Research in Science Education, v. 43, p. 1-18, 2019d. 
MICHA, D.; FERREIRA, M. Física no esporte - parte 1: saltos em esportes coletivos. Uma motivação para o estudo da mecânica através da análise dos movimentos do corpo humano a partir do conceito de centro de massa. Revista Brasileira de Ensino de Física, v. 35, n. 3, p. 3301, 2013.

NORBERTO ROCHA, J. Museus e centros de ciências itinerantes: análise das exposições na perspectiva da Alfabetização Científica. 2018. Tese (Doutorado em Educação) - Faculdade de Educação, Universidade de São Paulo, São Paulo. DOI: 10.11606/T.48.2018.tde03122018-122740.

ROSCHELLE, J. Learning in interactive environments: Prior knowledge and new experience. In: FALK, J.; DIERKING, D. (Eds.) Public Institutions for personal Learning: Establishing a research Agenda. Washington, DC: American Association of Museums, 1995.

SANTIAGO, R. B.; MARTINS, D. E.; NETO, O. P. O ensino de Física através do Futebol em um Pré-Vestibular Comunitário. In: II SIMPÓSIO NACIONAL DE ENSINO DE CIÊNCIA E TECNOLOGIA, II, 2010, Ponta Grossa, Paraná, Universidade Tecnológica Federal do Paraná. Anais...

SANTIAGO, R. B.; MARTINS, J. C.; DIAS, M. V.; PREUSSLER, O.; ANJOS, R. F. Interdisciplinaridade no Ensino: a física do esporte. In: SIMPÓSIO NACIONAL DE ENSINO DE FÍSICA, XVIII, 2009, Vitória, Espírito Santo. Anais...

SÁPIRAS, A. Aprendizagem em museus: uma análise das visitas escolares no Museu Biológico do Instituto Butantan. 2007. Dissertação (Mestrado em Educação) - Faculdade de Educação, Universidade de São Paulo, São Paulo.

SOJOURNER, E. J.; BURGASSER, A. J.; WEISE, E. D. Let's get physical: teaching physics through gymnastics. The Physics Teacher, v. 56, n. 43, 2018.

SPINNEY, J. Close encounters? Mobile methods, (post) phenomenology and affect. Cultural geographies, v. 22, n. 2, 2015.

VILlegas, J. O. R. La relación museo-escuela en el Museo de Antioquia: un estudio sobre percepciones de profesores, estudiantes y personal del museo. 2012. Dissertação (Mestrado) - Universidad de Antioquia, Facultad de Educación, Medellín.

VOURLIAS, K.; SEREGLOU, F. Physics and Sports: Let's get out of the classroom! In: International Physics Conference of the Balkan Physical Union, $9^{\text {th }}, 2016$. Proceedings... 
WAGENSBERG, J. Princípios fundamentales de la museología científica moderna. Alambique: Didáctica de las Ciencias Experimentales, Barcelona, n. 26, p.15-19, 2000.

YALOWITZ, S. Aquaria. In: GUNSTONE, R. Encyclopedia of Science Education. Dordrecht: Springer, 2015. 